\title{
Comprehensive Approach to Technical Conditions of Electromechanical Units in Mechatronic Systems
}

\author{
Stepanov Pavel ${ }^{1}$, Lagutkin Stanislav', Božek Pavol ${ }^{2}$, Nikitin Yury ${ }^{3, *}$ \\ ${ }^{1}$ Novouralsk Technological Institute (Branch of National Research Nuclear University “MEPhI”), Department of Mechanical \\ Engineering, Novouralsk, Russia \\ ${ }^{2}$ Institute of Applied Informatics, Automation and Mathematics, Faculty of Materials Science and Technology, Slovak University of \\ Technology, Trnava, Slovakia \\ ${ }^{3}$ Kalashnikov Izhevsk State Technical University, "Mechatronic Systems" Department, Izhevsk, Russia \\ *Corresponding author: doc_nikitin@mail.ru
}

Received October 08, 2014; Revised October 16, 2014; Accepted November 10, 2014

\begin{abstract}
Analysis of mechanical and electrical diagnostic parameters of electromechanical units is considered as an integrated approach. The relationship between mechanical, electric diagnostic parameters and technical conditions of the electric drive is investigated on the example of the stand consisting of the asynchronous motor, the coupling and a worm gear. The most sensitive diagnostic parameters were identified in case of various defects in electromechanical units. The change in the spectrum of vibration of the motor and the coefficients of the wavelet analysis of the electric current of the motor stator were investigated at idle and under load, in the absence and presence of the following defects: a decrease in the contact patch gear, misalignment coupling rims, as well as grazing rotor motor.
\end{abstract}

Keywords: diagnostics, electromechanical unit, mechatronic system, induction motor, worm gear, spectrum of vibration, electric current, wavelet analysis

Cite This Article: Stepanov Pavel, Lagutkin Stanislav, Božek Pavol, and Nikitin Yury, "Comprehensive Approach to Technical Conditions of Electromechanical Units in Mechatronic Systems.” American Journal of Mechanical Engineering, vol. 2, no. 7 (2014): 278-281. doi: 10.12691/ajme-2-7-22.

\section{Introduction}

With growth of automation in modern production the requirements for technological control rise. Thus, diagnostics of the equipment becomes the most perspective and rapidly developing aspect. Conveyors are one of a numerous examples of the automated equipment demanding diagnosing. To avoid a stop of this equipment, it is necessary to carry out diagnostics and to predict accidents of components which can arise at operation.

In this paper the mechanical and electrical diagnostic parameters, and also communication between them are considered on the example of the stand, which consist of the asynchronous motor, the coupling and the worm-andwheel reduction unit.

Issues of bearing, induction motor and electromechanical unit diagnostics are discussed in [1-13]. Modern diagnostic tools apply artificial intelligence techniques [1,2,3,4,7,11]. Fuzzy logic system is one of the efficient tools of equipment diagnostics [1,2,3,4,10].

Currently, artificial intelligence technologies are widely used for control and diagnostics of electric motors $[1,2,3,4,10,11,12,13]$.

\section{Experimental Studies}

To study the mechanical and electrical diagnostic parameters of electromechanical units the most frequently occurring defects were analyzed. Were revealed that often occur following defects: a reduction of the contact gear, misalignment coupling rims, as well as grazing rotor motor. Therefore, the laboratory bench is able to emulate these defects. The stand photo is shown in Figure 1.

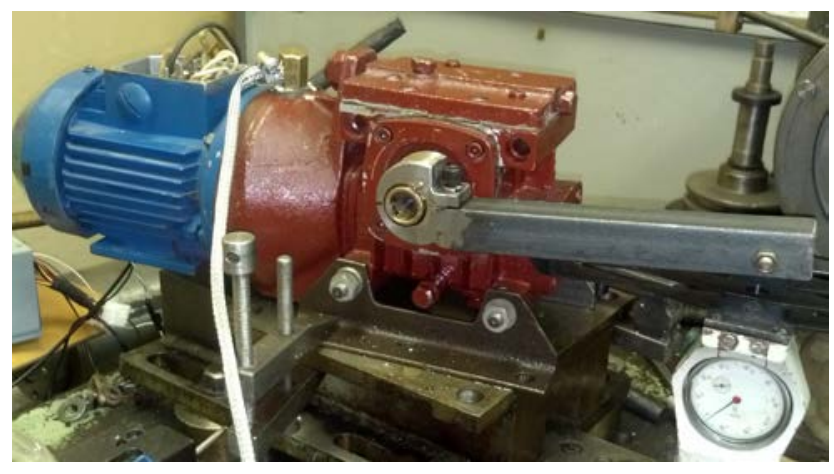

Figure 1. The laboratory stand

The vibrator inverter AP2019 (fastening on the coupling using a magnet) and current sensors LEM LA55P (installation on 3 phases of the asynchronous motor's stator) were used. All data were recorded in an idle mode (no-load conditions) and in a mode with load of wormand-wheel reduction unit $(\mathrm{M}=32 \mathrm{Nm})$. Electric motor power $\mathrm{P}=0,18 \mathrm{~kW}$. Rotation speed $\mathrm{N}=1350 \mathrm{rpm}$. Worm 
gear is MЧ-40M-31,5-47,6-51-5-1C-У3. The oscillograph Tektronix TDS3014 was used to record signals and process them in MathCAD and MathLAB software.

Data collection parameters: the number of samples $\mathrm{N}=$ 10000 , reading data time $\mathrm{t}=10 \mathrm{~s}$, the period $\mathrm{dt}=0.002 \mathrm{~s}$, sampling frequency $v=500 \mathrm{~Hz}$.

\subsection{Vibration Analysis}

Figure 2 and Figure 3 show the spectrum of vibration speed for completely serviceable electromechanical unit at idle and under load, respectively. In the second case, there is a general increase in the average amplitude of vibration speed from $2 \mathrm{~mm} / \mathrm{s}$ to $10 \mathrm{~mm} / \mathrm{s}$ and the appearance of the rotating vibration speed frequency $\mathrm{F}_{\mathrm{r} 1}=22,4 \mathrm{~Hz}$ (vibration speed amplitude $20 \mathrm{~mm} / \mathrm{s}$ ), its second (vibration speed amplitude $24 \mathrm{~mm} / \mathrm{s}$ ) and third harmonics (vibration speed amplitude $30 \mathrm{~mm} / \mathrm{s}$ ).

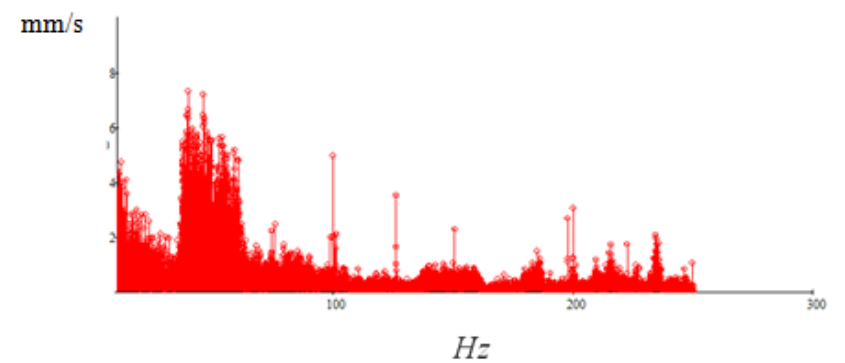

Figure 2. The spectrum of vibration speed for completely serviceable electrical motor in idling mode

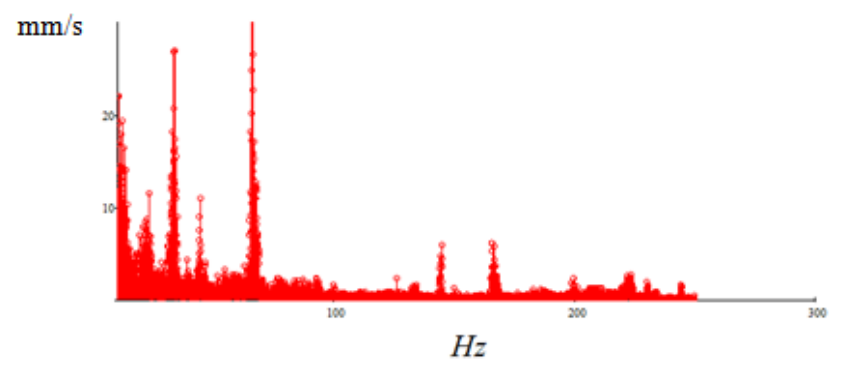

Figure 3. The spectrum of vibration speed for completely serviceable electrical motor in loading mode

Figure 4-Figure 6 show the spectrum of vibration speed with a decrease in the contact patch gear skewed rims clutch and grazing rotor motor, respectively.

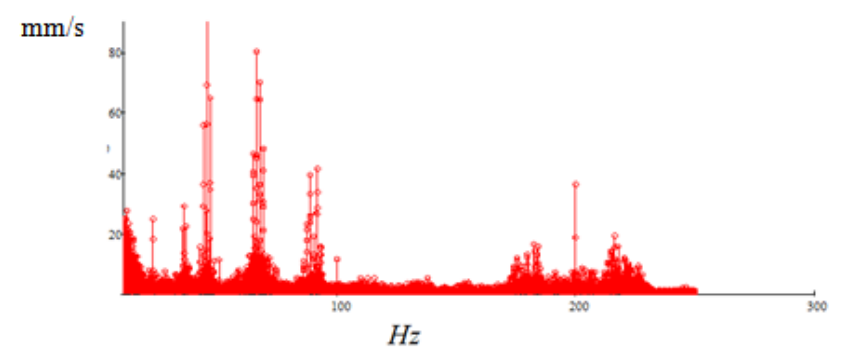

Figure 4. The spectrum of vibration speed of the electric motor with a decrease in the contact patch gear under load

By reducing the contact area the gear vibration amplitude is increased at the second harmonic frequency $\mathrm{F}_{\mathrm{r} 1}{ }^{2 \mathrm{X}}=44.8 \mathrm{~Hz}(30 \mathrm{~mm} / \mathrm{s})$ and the third harmonic (50 $\mathrm{mm} / \mathrm{s})$ at a frequency of tooth $\mathrm{F}_{\mathrm{z}}=45 \mathrm{~Hz}(90 \mathrm{~mm} / \mathrm{s})$ and the second harmonic $(45 \mathrm{~mm} / \mathrm{s})$. An increase of the amplitude for the tooth frequency and its harmonics is higher about 9-10 times in compare with intact mode under load.

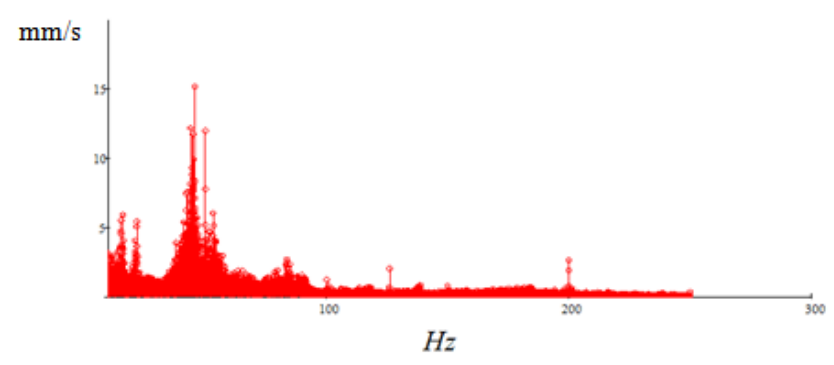

Figure 5. The spectrum of vibration speed of the electric motor with a skew rims clutch under load

With a skew rims clutch under the load an increase of amplitude coupling rate on the rotating does not occur (7 $\mathrm{mm} / \mathrm{sec}$ ), but there is a lateral harmonic (frequency $30 \mathrm{~Hz}$, amplitude $6 \mathrm{~mm} / \mathrm{s}$ ). In the spectrum can also be seen a second harmonic frequency, its amplitude also does not increases.

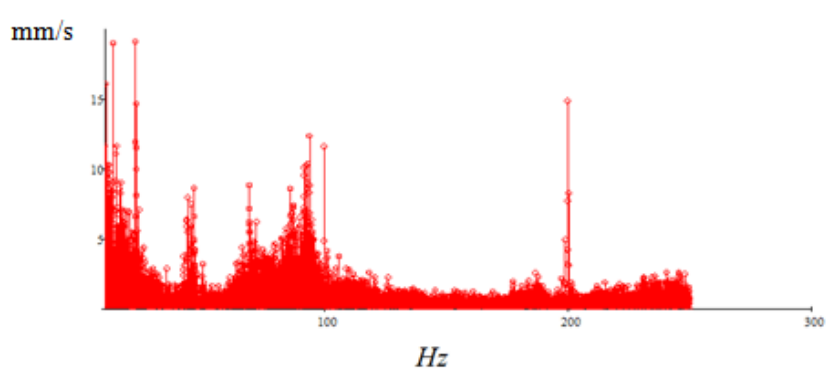

Figure 6. The spectrum of vibration speed of the motor with grazing rotor induction motor under load

In the event of grazing rotor the amplitude on the rotating frequency also increases $(18 \mathrm{~mm} / \mathrm{s})$. There is fractional harmonic (frequency about $12 \mathrm{~Hz}-0,5 \cdot \mathrm{F}_{\mathrm{r} 1}$, amplitude $17 \mathrm{~mm} / \mathrm{s}$ ). A characteristic feature of this spectrum can be called the emergence of the "energy hump" at frequencies from $80 \mathrm{~Hz}$ to $100 \mathrm{~Hz}$. This is because the grazing on the rotor was produced by impact the induction motor of the fan blades ( 4 blades).

\subsection{Analysis of the Current}

Wavelet analysis of the electric current of the three phases of the motor stator was performed. Daubechies wavelets $(\mathrm{db}-8)$ were used. For the analysis of the motor current a Table 1 was correspond to the coefficients of the wavelet transform bands of the spectrum of the motor current.

Table 1. Frequency Bands of the stator current with wavelet transform

\begin{tabular}{|c|c|c|}
\hline Value dt (s) & Specification & Sub-band (Hz) \\
\hline \multirow{4}{*}{0.002} & $\mathrm{~d} 1$ & $250 \ldots 500$ \\
\cline { 2 - 3 } & $\mathrm{d} 2$ & $125 \ldots .250$ \\
\cline { 2 - 3 } & $\mathrm{d} 3$ & $62.5 \ldots 125$ \\
\cline { 2 - 3 } & $\mathrm{d} 4$ & $31.25 \ldots 62.5$ \\
\cline { 2 - 3 } & $\mathrm{d} 5$ & $15.63 \ldots 31.25$ \\
\cline { 2 - 3 } & $\mathrm{d} 6$ & $7.81 \ldots 15.63$ \\
\cline { 2 - 3 } & $\mathrm{d} 7$ & $3.9 \ldots 7.81$ \\
\hline
\end{tabular}

Figure 7-Figure 11 show the data obtained under the same experimental conditions. 


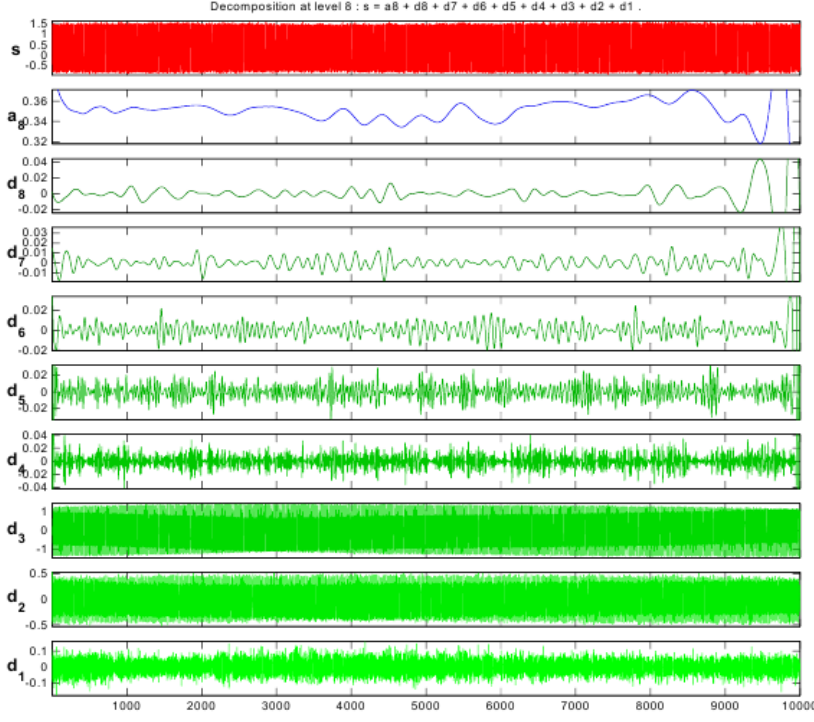

Figure 7. The electric current of the third phase of the serviceable motor stator and its wavelet transform in idling mode

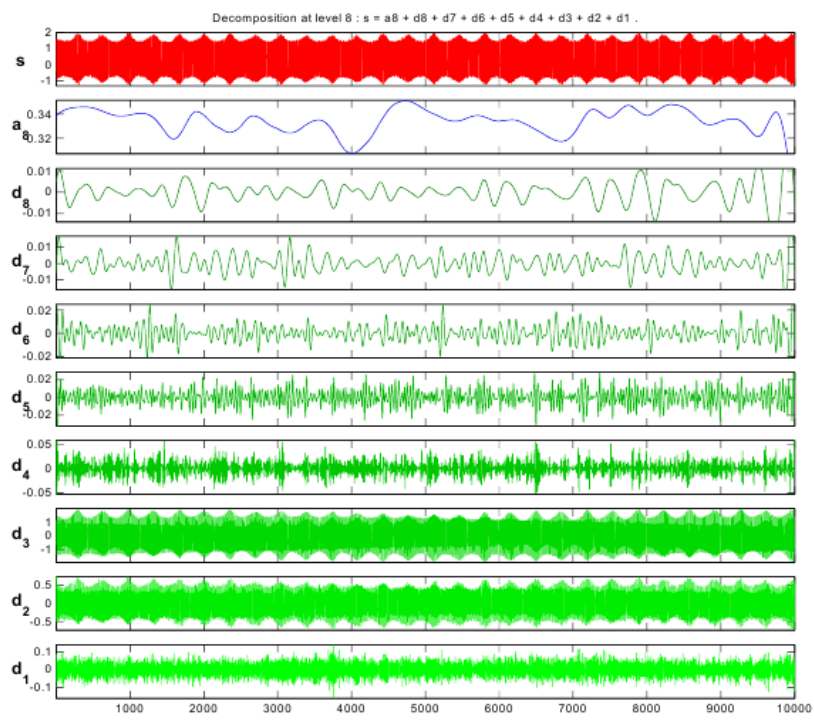

Figure 8. The electric current of the third phase of the motor stator and its serviceable wavelet transformation under load

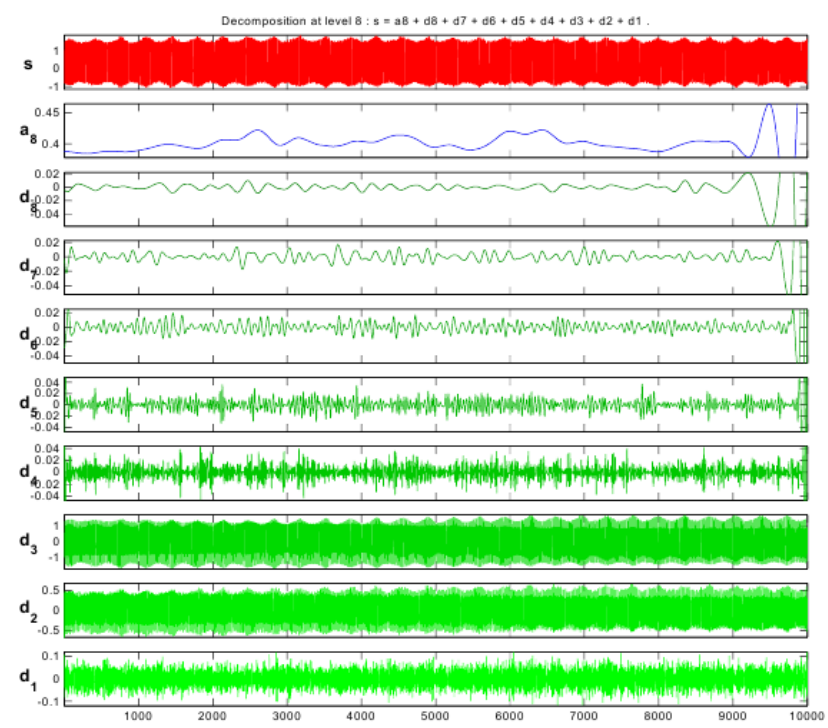

Figure 9. The electric current of the third phase of the motor stator and its wavelet transform decreases the contact gear
Figure 9 shows the change in amplitude coefficient d5 c 0.02 to 0.03 (with peaks up to $0.04-0.05$ ) compared with intact electric motor (Figure 8). This slight change of the coefficient is explained by the presence of the kinematic chain between the motor and the gear.

The increase in the coefficient of $\mathrm{d} 5$ is also possible to explain the relevant frequency range (15.63...31.25 Hz). It is the reverse speed. Increase in the amplitude at this frequency and its harmonics were recorded also in the analysis of vibration speed. Wavelet analysis of the stator current for a given defect showed the possibility of determining the frequency range in which it is necessary to conduct a detailed analysis of the spectrum of vibration speed.

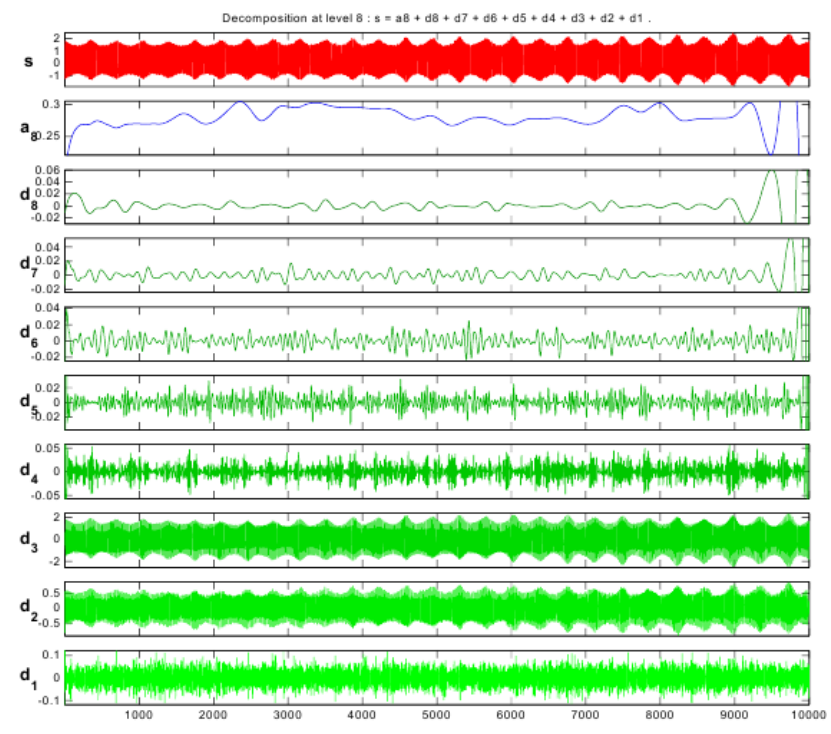

Figure 10. The electric current of the third phase of the motor stator and its wavelet transform with misalignment rims clutch under load

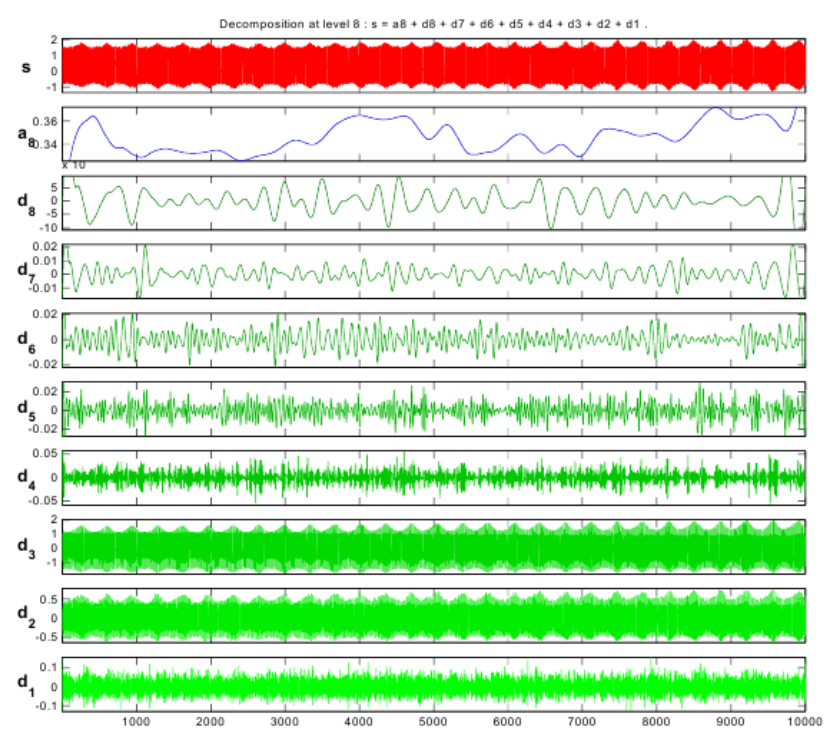

Figure 11. The electric current of the third phase of the stator of the drive and its wavelet transform tripping on the rotor of the motor under load

Figure 10 shows the change in amplitude ratio d3 from 1.2 to 1.8 (with peaks to 2) as compared with intact electrical motor under load (Figure 8). The frequency range in which the effect this ratio ranges from 62.5 to 125 $\mathrm{Hz}$. Here there are 3-5 reverse rotation frequency harmonics that have the greatest impact on the increase of 
the amplitude ratio. Their appearance can be explained by the fact that the motor coupling misalignment rims need to put more effort in the points skew rotation of the rotor. From here there is torque ripple that leads in increase the current.

Figure 11 also shows the change of amplitude coefficient d3 c 1.2 to 1.7 (with peaks to 1.9) as compared with intact electrical motor under load (Figure 8). This ratio increases for the same reason as in the previous case (Figure 10). But here there is a clear connection between the spectrum of vibration speed. In Figure 6, you can see the "energy hump." Thus, in the vicinity of the zone of the stator current defect analysis showed the best results.

Analysis of the results showed an increase in the value of certain factors in the event of defects of electric motor. Each coefficient corresponds to its frequency spectrum of the electric current. Finding the dependence of the coefficients of vibration speed makes possible the creation of a database for a particular hardware defects.

\section{Conclusion}

In this paper the diagnostic parameters for determination of current status of electromechanical system were allocated. The connection between these parameters was established by imitation of some defects.

The developed hybrid system allows to estimate a status of the equipment in mechanical and electrical parameters that leads to the most reliable and exact results.

By the results of this research the intelligence system for decision-making founded on algorithms of fuzzy logic is developed.

\section{Acknowledgement}

The reported study was partially supported by RFBR, research project No. 13-08-01181 a.

\section{References}

[1] Abramov I., Nikitin Yu., Abramov A., Sosnovich E., Božek P., Stollmann V. "Diagnosis of rolling mill line gear-motors" in International Conference on Innovative Technologies, IN-TECH 2014, Faculty of Engineering University of Rijeka, 155-158.

[2] Abramov, I., Nikitin, Yu., Zorina, O., Božek, P., Stepanov, P., Stollmann, V., "Monitoring of technical condition of motors and bearigs of woodworking equipment", Acta Facultatis Xylologiae Zvolen, Technick univerzita vo Zvolene, 56(2). 97-104. Dec., 2014.

[3] Abramov, I.V., Abramov, A.I., Nikitin, Yu.R., Sosnovitch, E.V., "Brushless DC motor diagnostic model" in Technological Forum 2014: 5 International technical conference, Czech technical university in Prague, 173-177.

[4] Abramov, I.V., Nikitin, Yu.R., Abramov, A.I., Sosnovich, E.V., Božek, P., "Control and diagnostic model of brushless DC motor", Journal of Electrical Engineering, Vol. 65, No. 5. 277-282. Oct., 2014.

[5] Cowan, R.S., Winer, W.O., Handbook of Technical Diagnostics: Fundamentals and Application to Structures and Systems, Machinery Diagnostics, Springer Berlin Heidelberg, 2013, 387410.

[6] Dovban', S.N., Veselov, O.V., “Technical diagnostics of electromechanical systems based on the analysis of distorted output signal“, Automation and Remote Control, Volume 73, Issue 11, 1902-1909. November 2012.

[7] Hammer, M., Šimková, M., Ministr, M. “Artificial Intelligence in Diagnostics of Electric Machines: Recent Advances in Mechatronics", 2010, 139-144.

[8] Hetmanczyk, M.P., Swider, J.A., "Selected vibrational symptoms in transient states of AC drives", International Journal of Dynamics and Control, Feb.,2014. [Online] Available: http://link.springer.com/article/10.1007/s40435-014-00620/fulltext.html. [Accessed Dec. 2, 2014].

[9] Lee, Y.S., Kim, Y.W., “Condition monitoring of induction motors for vertical pumps with the current and vibration signature analysis“, Experimental analysis of nano and engineering materials and structures. Springer, Dordrecht, 2007, 419-420.

[10] Nikitin, Y., Abramov, I., "Mechatronic modules diagnosis by use of fuzzy sets" in Proceedings of 14-th International Conference on Mechatronics, Trencinske univerzitné, 109-111.

[11] Nikitin, Y.R., Abramov, I.V., "CNC machines diagnostics" in Proceedings 13-th International Simposium on Mechatronics, Trencinske univerzitné, 89-91.

[12] Stepanov, P., Lagutkin, S., "Research of Electric and Mechanical Diagnostic Parameters of Drive Equipment", Applied Mechanics and Materials. Trans Tech Publications, Vol.683. 177-182. Oct., 2014.

[13] Stepanov, P., Nikitin, Yu., "Diagnostics of Mechatronic Systems on the Basis of Neural Networks with High-Performance Data Collection" in Mechatronics 2013: Recent Technological and Scientific Advances, Springer Intrenational Publishing Swizerland, 433-440. 